\title{
Mycorrhizal Circuit in the Root of Avena Sativa
}

\author{
Vlad STOIAN $^{1}$, Roxana VIDICAN ${ }^{1 *}$ and Ioan ROTAR ${ }^{1}$ \\ ${ }^{1}$ Department of Plant Culture. University of Agricultural Sciences and Veterinary Medicine Cluj-Napoca \\ *Corresponding author: roxana.vidican@usamvcluj.ro
}

Bulletin USAMV series Agriculture 72(2)/2015

Print ISSN 1843-5246; Electronic ISSN 1843-5386

DOI 10.15835/buasvmcn-agr: 11575

\begin{abstract}
Oats has the capacity to develop a strong radicular biomass in the soil, alongside a good adaptability to cold climats, characters which favor it over other cereals in the areas with lower temperatures and high humidity. The simultaneous evolution with the symbiotic fungi allowed the premisis for a stronger installation of mychorrizal fungi, stimulated by the radicular exudate of the oats. The transfer of nutritive elements occurs between the fungi and plant, at the level of hyphal and arbuscular interfaces. The degree of mychorrization is greater in the senescent areas of the roots, while the transfer of nutritive elements thorugh the arbuscular circuit is higher in the freshly developed roots.
\end{abstract}

Keywords: oats, greenhouse, hyphal circuit, absorption potential.

\section{INTRODUCTION}

Among cereals, oats has the ability to develop the largest root system with a good capacity to exploit nutrient resources from slightly soluble compounds from soil. Agrobiological particularities have established it as the cereal for cool, wet climates. Avena sativa species have the ability to stimulate the growth of mycorrhizal fungi reserve in the soil, being a crop with high potential for restoration techniques of the natural soil fertility.

\section{AIMS AND OBJECTIVES}

The evaluation of root system architecture of Avena sativa species. Separation of active root structures based on absorption capacity. Quantification of the size of hyphal mycorrhizal network and identification of connecting areas of the active absorption circuit with the transfer circuit.

\section{MATERIALS AND METHODS}

Oat plants were grown in pots in a controlled environment. The root surface was analyzed at the root branching points, separately for each type of roots ( $\mathrm{Or}$ I, O r II, O r III) perfoming the calculation of the parameters of mycorrhization. Assessment of the mychorrization level was performed based on the indicators proposed by Trouvelot et al. (1986, quoted by www2.dijon.inra.fr), frequency (freq), colonization intensity in the system (int sys) and in root segments (int seg), arbuscularity in the system (arb sys) and in root segments (arb $\mathrm{seg}$ ), rounded by the degree of colonization (col deg) specific to each analyzed radicular system (Stoian, 2011). Statistical analysis were conducted with Tukey.HSD test, from "agricolae" package (de Mendiburu et al., 2014) in R Studio (Team R, 2014).

\section{RESULTS AND DISCUSSION}

The colonization frequency decreses insignificantly with the root ramification and yielding of young roots. The colonization intensity ranges between $40-70 \%$, higher in the young root framgments. The arbuscular interface is installed predominantely in the fragments of young roots, with significant differences between the values 
Tab. 1. Mycorrhizal parameters in all branching levels

\begin{tabular}{ccccccc}
\hline $\begin{array}{c}\text { Root } \\
\text { architecture }\end{array}$ & Freq & Int sys & Int seg & arb seg & Arb sys & Col deg \\
\hline O r I & $93.81^{\mathrm{a}}$ & $43.33^{\mathrm{a}}$ & $55.56^{\mathrm{a}}$ & $0.58^{\mathrm{c}}$ & $0.26^{\mathrm{c}}$ & $40.80^{\mathrm{a}}$ \\
\hline O r II & $90.07^{\mathrm{a}}$ & $58.68^{\mathrm{a}}$ & $64.53^{\mathrm{a}}$ & $35.60^{\mathrm{s}}$ & $20.96^{\mathrm{a}}$ & $52.84^{\mathrm{a}}$ \\
\hline O r III & $84.45^{\mathrm{a}}$ & $50.47^{\mathrm{a}}$ & $69.96^{\mathrm{a}}$ & $30.69^{\mathrm{b}}$ & $15.48^{\mathrm{b}}$ & $42.65^{\mathrm{a}}$ \\
\hline Note: Different letters between parameters denote significant differences (Tukey.HSD test, $\mathrm{p}<0.05$ ). & &
\end{tabular}

obtained on each radicular architecture level. The colonization degree ranges between $40-50 \%$ values, indicating a well-balanced colonization of the radicular cortex and a well-conditioned development of the symbiotic plant-fungi system.

The well developed root system of oats stimulates a strong installation of symbiotic vesicular-arbuscular fungi. In young roots, a large number of arbuscules are formed, indicating the existence of a functional interface for exchange of nutrients between the host plant and fungal partner.

\section{CONCLUSION}

The mycorrhization level is relatively constant over the entire root system surface, in young areas dominating the ephemeral (impermanent) structures for intracellular transfer of nutrients.

\section{REFERENCES}

1. de Mendiburu F (2014). agricolae: Statistical Procedures for Agricultural Research. R package version 1.2-1. http:// CRAN.R-project.org/package=agricolae.

2. Stoian HV (2011).Studiul simbiozelor micoriziene în unele ecosisteme de pajişti din zona Munților Apuseni. Teză de doctorat - USAMV Cluj- Napoca.

3. Team R (2014). RStudio: Integrated Development for R. RStudio, Inc., Boston, MA. URL http://www.RStudio.com/ ide.

4. ${ }^{* * *}$ www2.dijon.inra.fr 